\title{
HIIT produces increases in muscle power and free testosterone in male masters athletes
}

\author{
P Herbert ${ }^{1}$, LD Hayes ${ }^{2}$, NF Sculthorpe ${ }^{3}$ and FM Grace ${ }^{4}$ \\ 'School of Sport, Health and Outdoor Education, Trinity Saint David, University of Wales, Wales, UK \\ ${ }^{2}$ Active Ageing Research Group, Department of Medical and Sport Sciences, University of Cumbria, Lancaster, UK \\ ${ }^{3}$ Institute of Clinical Exercise and Health Science, University of the West of Scotland, Scotland, UK \\ ${ }^{4}$ Faculty of Health, Federation University, Victoria, Australia
}

Correspondence should be addressed to L D Hayes

Email

lawrence.hayes@cumbria. ac.uk

\begin{abstract}
High-intensity interval training (HIIT) improves peak power output (PPO) in sedentary aging men but has not been examined in masters endurance athletes. Therefore, we investigated whether a six-week program of low-volume HIIT would (i) improve PPO in masters athletes and (ii) whether any change in PPO would be associated with steroid hormone perturbations. Seventeen male masters athletes ( $60 \pm 5$ years) completed the intervention, which comprised nine HIIT sessions over six weeks. HIIT sessions involved six 30 -s sprints at $40 \%$ PPO, interspersed with 3 min active recovery. Absolute PPO $(799 \pm 205 \mathrm{~W}$ and $865 \pm 211 \mathrm{~W})$ and relative PPO $(10.2 \pm 2.0 \mathrm{~W} / \mathrm{kg}$ and $11.0 \pm 2.2 \mathrm{~W} / \mathrm{kg})$ increased from pre- to post-HIIT respectively ( $P<0.001$, Cohen's $d=0.32-0.38$ ). No significant change was observed for total testosterone $(15.2 \pm 4.2 \mathrm{nmol} / \mathrm{L}$ to $16.4 \pm 3.3 \mathrm{nmol} / \mathrm{L}(P=0.061$, Cohen's $d=0.32))$, while a small increase in free testosterone occurred following HIIT $(7.0 \pm 1.2 \mathrm{ng} / \mathrm{dL}$ to $7.5 \pm 1.1 \mathrm{ng} / \mathrm{dL}$ pre- to post-HIIT $(P=0.050$, Cohen's $d=0.40)$ ). Six weeks' HIIT improves PPO in masters athletes and increases free testosterone. Taken together, these data indicate there is a place for carefully timed HIIT epochs in regimes of masters athletes.
\end{abstract}

$\begin{aligned} & \text { Key Words } \\ & \text { - cortisol } \\ & \text { - HIIT } \\ & \text { - power } \\ & \text { - steroid } \\ & \text { - testosterone }\end{aligned}$

Endocrine Connections (2017) 6, 430-436

\section{Introduction}

Peak muscle power is an important determinant of athletic performance across the lifespan that declines with age (1) and is accompanied by a precipitous decline in serum testosterone (2). Both present a noteworthy impediment to the competitive masters athlete and negotiating this physiological decline requires a training program tailored for the older athlete. However, in contrast to the abundant evidence base for optimal training and performance for younger athletes, there is a paucity of comparable literature for the masters athlete, and a broad assumption that recovery profiles are analogous across the aging continuum. In the absence of age-specific exercise training guidelines, older athletes typically adhere to training routines comparable with their younger counterparts.
High-intensity interval training (HIIT) is a timeefficient strategy to achieve health (3) and performance (4) benefits in younger cohorts, which contradicts the recommended minimum physical activity threshold guidelines (150 min/week) (5). Six HIIT sessions has over a two- to three-week period improved muscle force in physically active young men and women (6), and sixweek low-frequency HIIT improved peak oxygen uptake $\left(\mathrm{VO}_{2 \text { peak }}\right)$ and quality of life in both sedentary and athletic aging men (7). There is some evidence that older persons take longer to recover from strenuous exercise than their younger counterparts (8), which can exceed five days (9). More recently, our research group identified that aging men take longer to recover from a single HIIT session
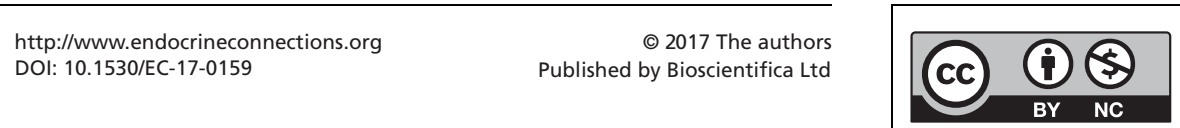

This work is licensed under a Creative Commons Attribution-NonCommercial 4.0 International License. 
than younger counterparts, highlighting HIIT programs that employ traditional (three sessions/week) regimens are likely to be overly strenuous for the aging athlete (10) and support the suggestion that athletes of different age groups may require differing recovery profiles. This may partly explain why endurance-focused masters athletes partake in high-volume aerobic training (11), and substituting their normal training regimens with comparatively minuscule volumes of HIT would appear counterintuitive.

The relationship between testosterone and exercise in older males is a topic of ongoing debate and equivocal research findings $(12,13,14)$. Conclusions have primarily relied on associative data from epidemiological studies $(15,16,17)$. More recently, our group reported increased total testosterone (TT), but not free testosterone (free-T), in sedentary older men following six-week moderate aerobic training (18). Subsequently, we observed increased free-T following the addition of HIIT to this group (13). Conversely, Sylta and coworkers (19) reported a decrease in TT and free-T following four-week HIIT in well-trained young cyclists. These authors also reported that PPO increased concomitantly, which would appear counterintuitive given the pervasive belief that muscle power is positively influenced by testosterone. While Sylta and coworkers (19) observed decreased testosterone following HIIT in young athletes, the influence of HIIT on androgens of the master athlete remains unknown.

HIIT has been shown to improve maximal aerobic power in masters athletes (7), and PPO and free-T in untrained older participants $(13,20)$. Moreover, HIIT increased PPO, but decreased TT and free-T in young trained participants (19). However, the effect of HIIT on PPO, TT and free-T in masters athletes is currently unknown. One of the most important articles on HIIT exercise (20) highlighted the lack of HIIT studies in aging cohorts. Surprisingly, until a recent study of HIIT in sedentary aging men (21), there were no data on the impact of HIIT exercise on muscle power in aging men. With these aspects in mind, the present study set out to examine the influence of substituting normal exercise training with a six-week (nine sessions) low-volume HIIT program on PPO, TT, free-T, cortisol and the TT:cortisol ratio, in male masters athletes. We hypothesized that (i) six weeks of low-frequency HIIT would improve PPO compared with normal exercise training and (ii) systemic steroid hormones would be unchanged following lowfrequency HIIT in masters athletes.

\section{Materials and methods}

\section{Participants}

Following familiarization with experimental procedures and approval to exercise by their general practitioner, participants provided written informed consent prior to enrolment to the study, which was approved by the University of the West of Scotland Ethics Committee. Experiments were performed in accordance with the ethical standards of the Helsinki Declaration (2013). Seventeen male masters' athletes $(60 \pm 5$ years, with a stature of $173 \pm 6 \mathrm{~cm}$, body mass of $78 \pm 12 \mathrm{~kg}$, and peak oxygen uptake of $41 \pm 6 \mathrm{mLkg} / \mathrm{min}$ (as previously determined \{7\})) completed the investigation. Participants were highly active exercisers and had been so for the previous $>30$ years. They consisted of masters competitors in waterpolo, triathlon, track cycling, road cycling and distance running. Participants underwent two familiarization sessions before initial testing and arrived at the laboratory in the morning, following an overnight fast.

\section{Phase A-B: capturing habitual exercise training}

To allow for the comparison of HIIT with participants' normal training regimens, the study necessitated three distinct assessment phases (phase A, B and C), each lasting one week, which were separated by six weeks. Between assessment phases A and B, participants were instructed to maintain their habitual training practices, which were recorded by heart rate telemetry and training diaries. This included type, frequency, duration and intensity of exercise. Participant weekly average time spent $<65 \%$ heart rate reserve (HRR), and $\geq 65 \%$ HRR totaled $214 \pm 131 \mathrm{~min} /$ week and $67 \pm 52 \mathrm{~min} /$ week respectively.

\section{Phase B-C: high-intensity interval training (HIIT)}

From phase B to C, participants underwent a supervised HIIT program. HIIT sessions were performed once every five days, for six weeks (nine sessions in total). Rationale for this program is provided by our previous work which identified five days was required for recovery of PPO following HIIT among older males (10). Each session consisted of $6 \times 30$-s sprints at $40 \%$ PPO (determined during familiarization) interspersed with $3 \mathrm{~min}$ active recovery on a cycle ergometer (Wattbike Ltd., Nottingham, UK). Sessions were conducted in groups of four to six participants and were the sole exercise performed during this period. To allow for comparison with existing

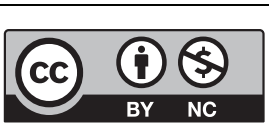

This work is licensed under a Creative Commons Attribution-NonCommercial 4.0 International License. 
literature, training intensities were compared with power achieved at $\mathrm{VO}_{2 \text { peak }}$. In the majority of cases, $40 \%$ PPO was greater than power at $\mathrm{VO}_{2 \text { peak }}$. In three cases, it exceeded $90 \%$ of power at $\mathrm{VO}_{2 \text { peak }}(92 ; 96 ; 98 \%)$. Mean training intensity equated to $126 \pm 22 \%$ of power output at $\mathrm{VO}_{2 \text { peak }}$.

\section{Peak power output assessment}

The Herbert $6 \mathrm{~s}$ cycling test (22) consisted of a $6 \mathrm{~s}$ maximal sprint against constant resistance on an airbraked cycle ergometer (Wattbike Ltd., Nottingham, UK). For each subject, the damper resistance was set at 10 . Participants completed a standardized 3 min warm-up involving pedaling at $60 \mathrm{rpm}$ interspersed with three $\sim 2 \mathrm{~s}$ sprints. The test commenced from a standing start (i.e. not pedaling). Participants were verbally encouraged throughout the test to promote maximal effort. A recovery period of $5 \mathrm{~min}$ was permitted between the warm-up and the test. Power output was calculated each second for the duration of the test and peak power over $1 \mathrm{~s}$ was recorded.

\section{Blood draws and analysis}

Blood samples from each participant were collected at phase A, B and C, at 07:00-09:00 h, 48-72 h following the last exercise session as previously described (23, $24,25,26)$. Serum concentrations of TT, sex hormonebinding globulin (SHBG) and cortisol were determined by electrochemiluminescent immunoassay on the E601 module of the Roche Cobas 6000. Inter-assay CVs over a six-month period were $4.5,2.4$ and $4.2 \%$ for TT, SHBG and cortisol respectively. Analyses were carried out in a clinical pathology laboratory (Royal Glamorgan Hospital, Wales, UK). Free-T was calculated using the Vermeulen formula (27), which has been validated against equilibrium dialysis (28). The testosterone:cortisol ratio (T:C) was calculated by the following equation: $\mathrm{T}: \mathrm{C}=100 \cdot(\mathrm{TT} \div$ cortisol $)$.

\section{Statistical analysis}

Following a Shapiro-Wilk test of normality and Levene's test for homogeneity of variance, a one-way analysis of variance (ANOVA) with post hoc Bonferroni correction was conducted to determine differences between phase A, B and C. Alpha level was set a priori at $P \leq 0.05$, and effect size (Cohen's $d$ ) was calculated for paired comparisons. Data are presented as mean \pm standard deviation (s.D.).

\section{Results}

\section{Phase A to B: maintenance of high-volume aerobic training}

Statistical power was confirmed as 0.994 for absolute PPO. There was no change to absolute PPO $(766 \pm 163 \mathrm{~W}$ and $799 \pm 205 \mathrm{~W} ;$ Cohen's $d=0.18)$, relative PPO $(9.7 \pm 1.8 \mathrm{~W} / \mathrm{kg}$ and $10.2 \pm 2.0 \mathrm{~W} / \mathrm{kg}$; Cohen's $d=0.26)$, TT $(15.5 \pm 2.5 \mathrm{nmol} / \mathrm{L}$ and $15.2 \pm 4.2 \mathrm{nmol} / \mathrm{L}$; Cohen's $d=0.09)$, SHBG $(45.3 \pm 12.5 \mathrm{nmol} / \mathrm{L}$ and $48.5 \pm 16.9 \mathrm{nmol} / \mathrm{L}$; Cohen's $d=0.22)$, free-T $(7.2 \pm 1.1 \mathrm{ng} / \mathrm{dL}$ and $7.0 \pm 1.2 \mathrm{ng} / \mathrm{dL}$; Cohen's $d=0.17)$, and T:C (5.4 \pm 3.0 and 6.3 \pm 2.7 Cohen's $d=0.32$ ) from phase A to $\mathrm{B}$ respectively (all $P>0.05$ ). Cortisol decreased moderately from $345 \pm 138 \mathrm{nmol} / \mathrm{L}$ to $278 \pm 114 \mathrm{nmol} / \mathrm{L}(P=0.038$; Cohen's $d=0.53)$.

\section{Phase B to C: substitution of high-volume aerobic training with HIIT}

Absolute PPO $(799 \pm 205 \mathrm{~W}$ and $865 \pm 211 \mathrm{~W}(P<0.001$, Cohen's $d=0.32))$, and relative PPO $(10.2 \pm 2.0 \mathrm{~W} / \mathrm{kg}$ and $11.0 \pm 2.2 \mathrm{~W} / \mathrm{kg}(P<0.001$, Cohen's $d=0.38))$, were increased from pre- to post-HIIT respectively (Fig. 1).

Blood parameters are displayed in Figs 2 and 3 . There was no change to TT $(15.2 \pm 4.2 \mathrm{nmol} / \mathrm{L}$ and $16.4 \pm 3.3 \mathrm{nmol} / \mathrm{L}$ pre- and post-HIIT respectively $(P=0.061$, Cohen's $d=0.32))$ or SHBG $(48.5 \pm 16.9 \mathrm{nmol} / \mathrm{L}$ and $50.6 \pm 14.7 \mathrm{nmol} / \mathrm{L}$ pre- and post-HIIT respectively $(P=0.204$, Cohen's $d=0.13))$ as a result of HIIT. However, there was a small increase in free- $\mathrm{T}(7.0 \pm 1.2 \mathrm{ng} / \mathrm{dL}$ and $7.5 \pm 1.1 \mathrm{ng} / \mathrm{dL}$ pre- and post-HIIT respectively $(P=0.050$, Cohen's $d=0.40)$ ), while a large increase in cortisol was observed $(275 \pm 119 \mathrm{nmol} / \mathrm{L}$ and $389 \pm 135 \mathrm{nmol} / \mathrm{L}$ preand post-HIIT respectively $(P=0.01$ Cohen's $d=0.90)$ ). Therefore, T:C was moderately decreased following HIIT $(6.3 \pm 2.7$ and $4.7 \pm 1.9$ pre- and post-HIIT respectively $(P=0.017$, Cohen's $d=0.69))$. No significant correlation existed between power profiles and any hormonal concentrations, at any phase, or delta change.

\section{Discussion}

The main finding of the present investigation was that replacing normal high-volume aerobic training with sixweek low-frequency HIIT improved absolute and relative PPO in male masters athletes and increased free-T. These data provide preliminary evidence to inform optimization of training practices in masters athletes.

This work is licensed under a Creative Commons Attribution-NonCommercial 4.0 International License. 

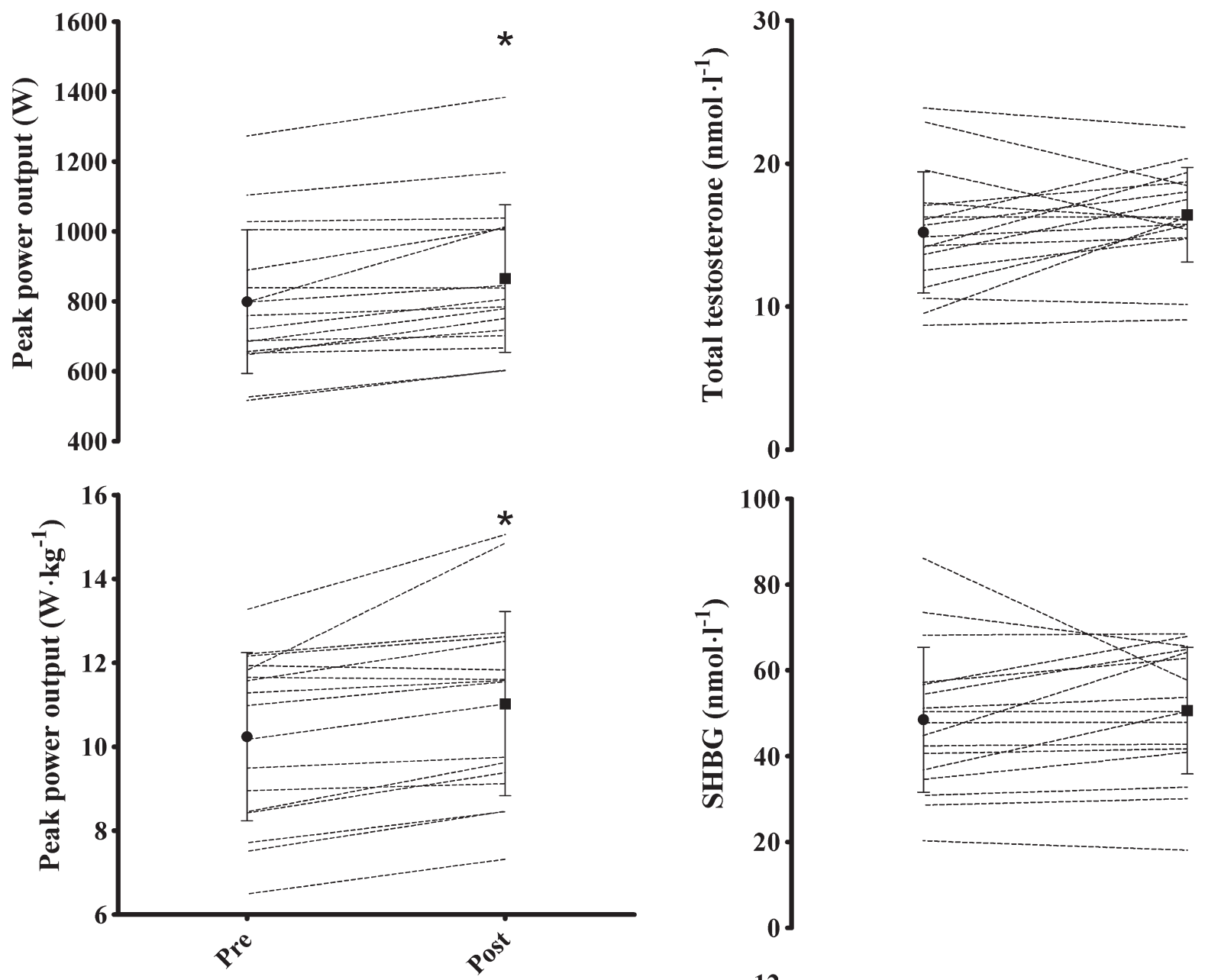

Figure 1

Absolute and relative peak power output in masters athletes pre and post six weeks of high-intensity interval training (HIIT). Dashed lines represent individual participants and marker and error bars represent mean \pm S.D. *Denotes significantly greater than pre-HIIT $(P \leq 0.05)$ as determined by Bonferroni correction.

In the present study, participants dramatically reduced their training volume from $\sim 281 \mathrm{~min} /$ week to $4.5 \mathrm{~min} /$ week (excluding active recovery) or $27 \mathrm{~min} /$ week (including active recovery). To the authors' knowledge, this is the first study to investigate the impact of reduced volume HIIT on PPO in masters athletes. The $\sim 8 \%$ increase in relative PPO is in line with previous investigations reporting improved performance following HIIT in young athletic populations $(29,30,31)$. For example, Sheykhlouvand and coworkers (29) observed HIIT induced a $9.7-12.2 \%$ greater increase in PPO during the Wingate Anaerobic Test compared to a moderate-intensity training group in professional male canoe polo athletes. Moreover, Stoggl and Sperlich (32) noted a greater increase

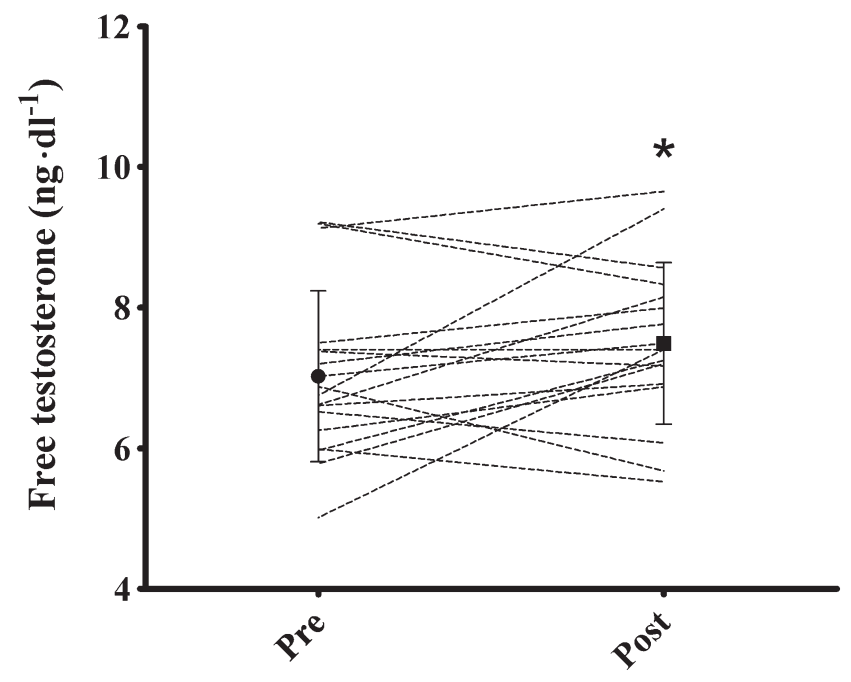

Figure 2

Total testosterone, sex hormone-binding globulin (SHBG), and free testosterone in masters athletes pre and post six weeks of high-intensity interval training (HIIT). Dashed lines represent individual participants and marker and error bars represent mean \pm S.D. *Denotes significant difference from pre-HIIT $(P \leq 0.05)$ as determined by Bonferroni correction.

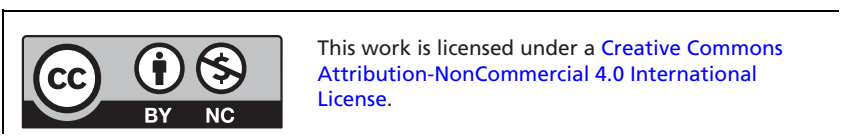



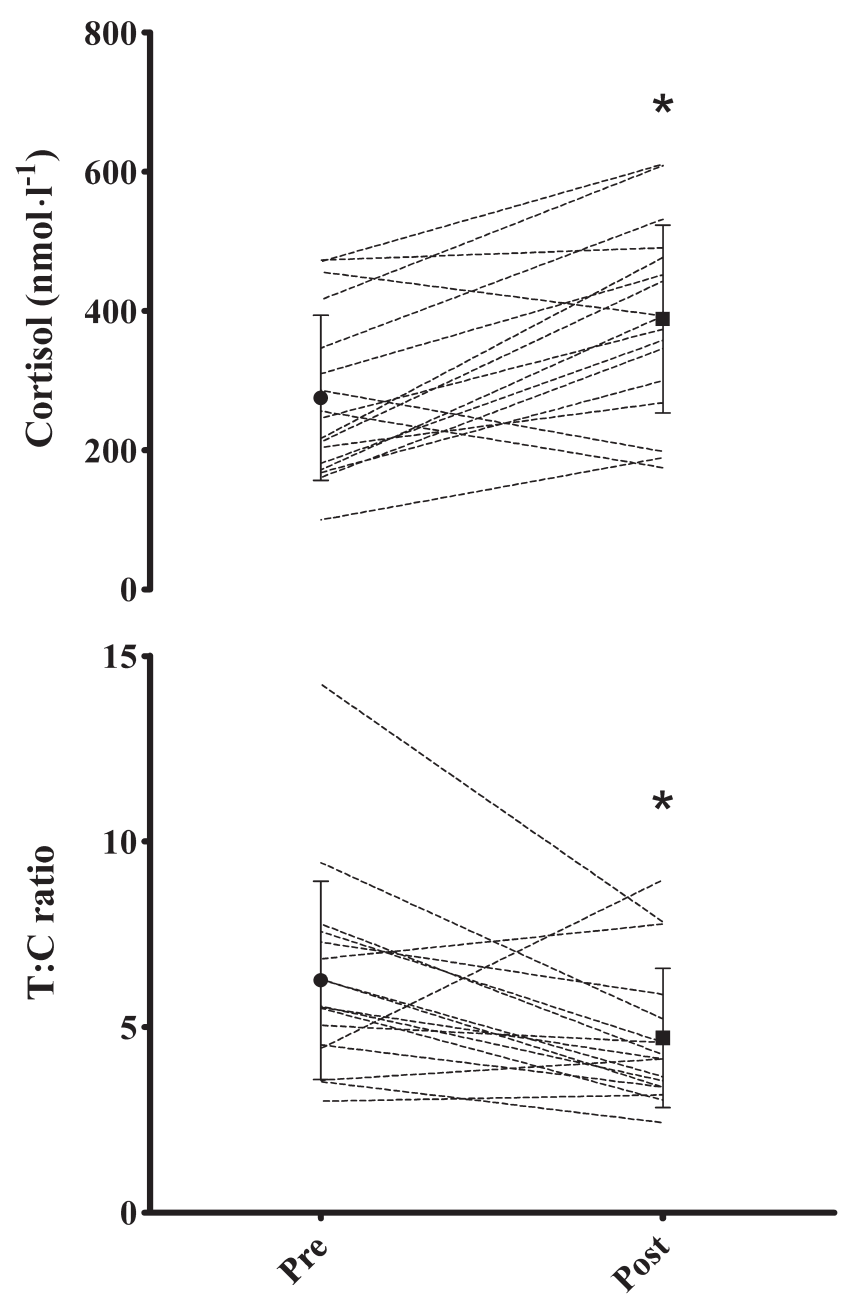

Figure 3

Cortisol, and the testosterone:cortisol (T:C) ratio, in masters athletes pre and post six-week high intensity interval training (HIIT). Dashed lines represent individual participants and marker and error bars represent mean \pm s.D. *Denotes significant difference from pre-HIIT $(P \leq 0.05)$ as determined by Bonferroni correction.

(+4.4 $\pm 2.8 \%)$ in PPO during an incremental test after HIIT, compared to high volume $(-1.5 \pm 4.9 \%)$, or threshold $(+1.8 \pm 4.8 \%)$, training in endurance athletes. These results were achieved despite the HIIT group training for $\sim 66 \mathrm{~h}$ over nine weeks, compared to $\sim 102 \mathrm{~h}$ and $\sim 84 \mathrm{~h}$ in the high volume, and threshold group respectively. Similarly, Naimo and coworkers (33) observed an increase of $12 \%$ PPO during the Wingate Anaerobic Test following HIIT compared to $\sim 2 \%$ following continuous training in collegiate ice hockey players.

We recently demonstrated that sedentary older males increased TT (but not free-T) following six-week moderate aerobic training (18) and free-T following HIIT (13). Conversely, Lovell and coworkers (14) reported no increase in basal TT or free-T following 16 weeks of aerobic, resistance or combined, exercise training in a group of older men ( 74 years). As both studies measured testosterone by immunoassay, and report similar CVs, the detection method is unlikely to explain differences in findings. We propose training intensity may mediate small differences in the testosterone response to exercise in older men, as we have now reported increased free-T in response to HIIT in both sedentary (13), and athletic older populations. We speculate that the training regimen employed by Lovell and coworkers (14) may not have achieved a threshold of exercise intensity to moderate the small changes in free- $\mathrm{T}$ demonstrated here. Moreover, as chronological age is known to dampen the physiological response to exercise (3) and participants in the study of Lovell and coworkers (14) were an average of $\sim 12$ years older, this may provide another account for differences between studies.

Adlercreutz and coworkers (34) previously suggested that a $30 \%$ reduction in the $\mathrm{T}: \mathrm{C}$ ratio may be indicative of overtraining. In the present study, the $\mathrm{T}$ : $\mathrm{C}$ ratio was reduced by $\sim 25 \%$, possibly indicating greater stress and recovery time associated with HIIT. However, a reduction in training volume makes overtraining unlikely, and overtraining would typically be associated with a reduction in PPO, rather than an increase. Moreover, Fry and coworkers (35) observed increased strength and increased $\mathrm{T}: \mathrm{C}$ ratio following overtraining in highintensity resistance exercise, calling into question the predictive ability of this blood biomarker to detect overtraining.

One limitation of the present investigation is the single-arm prospective cohort design, which does not permit comparison of PPO or free-T improvements with a control group, or a comparative moderate intensity training group. However, the magnitude of improvement in PPO with reduced volume HIIT warrants further enquiry in masters athletes with implementation of a randomized control trial (RCT). Moreover, until HIITinduced increases to free- $\mathrm{T}$ in the masters athlete are confirmed by equilibrium dialysis (the gold standard, but expensive and laborious), data in the present study remain preliminary.

The practical implication of the present study is that masters athletes can increase absolute and relative PPO, and free-T, by replacing high-volume aerobic training with low-volume HIIT. Our group has now demonstrated HIIT can improve PPO (as in the present study) and $\mathrm{VO}_{2 \text { peak }}$ (7) in masters athletes. To progress this field, further research 
is required to confirm whether improvements in labbased measures following HIIT translate to a performance advantage in masters competition.

In conclusion, six-week HIIT can induce large improvements in absolute and relative PPO, and small increases in free- $\mathrm{T}$ in male masters athletes. Taken together, this indicates there is a place for epochs of HIIT in training regimes of masters athletes, which may result in an improved anabolic environment. Given our previous work detailing that recovery of older adults takes five days to recover PPO following HIIT (10), carefully timed HIIT may be a pragmatic approach for maintaining athletic capability during periods of time restriction.

\section{Declaration of interest}

The authors declare that there is no conflict of interest that could be perceived as prejudicing the impartiality of the research reported.

\section{Funding}

This work did not receive any specific grant from any funding agency in the public, commercial, or not-for-profit sector.

\section{References}

1 Arampatzis A, Degens H, Baltzopoulos V \& Rittweger J. Why do older sprinters reach the finish line later? Exercise and Sport Science Reviews 201139 18-22. (doi:10.1097/JES.0b013e318201efe0)

2 Harman SM, Metter EJ, Tobin JD, Pearson J \& Blackman MR. Longitudinal effects of aging on serum total and free testosterone levels in healthy men. Journal of Clinical Endocrinology and Metabolism 200186 724-731. (doi:10.1210/jcem.86.2.7219)

3 Grace F, Herbert P, Elliott AD, Richards J, Beaumont A \& Sculthorpe NF. High intensity interval training (HIIT) improves resting blood pressure, metabolic (MET) capacity and heart rate reserve without compromising cardiac function in sedentary aging men. Experimental Gerontology 2017 [in press]. (doi:10.1016/j.exger.2017.05.010)

4 Garcia-Pinillos F, Camara-Perez JC, Soto-Hermoso VM \& LatorreRoman PA. A High Intensity Interval Training (HIT)-based running plan improves athletic performance by improving muscle power. Journal of Strength and Conditioning Research 201731 146-153. (doi:10.1519/JSC.0000000000001473)

5 Nelson ME, Rejeski WJ, Blair SN, Duncan PW, Judge JO, King AC, Macera CA \& Castaneda-Sceppa C. Physical activity and public health in older adults: recommendation from the American College of Sports Medicine and the American Heart Association. Medicine and Science in Sports and Exercise 200739 1435-1445. (doi:10.1249/ mss.0b013e3180616aa2)

6 Astorino TA, Allen RP, Roberson DW \& Jurancich M. Effect of highintensity interval training on cardiovascular function, $\mathrm{VO}_{2 \max }$, and muscular force. Journal of Strength and Conditioning Research 201226 138-145. (doi:10.1519/JSC.0b013e318218dd77)

7 Knowles AM, Herbert P, Easton C, Sculthorpe N \& Grace FM. Impact of low-volume, high-intensity interval training on maximal aerobic capacity, health-related quality of life and motivation to exercise in ageing men. Age 201537 25. (doi:10.1007/s11357-015-9763-3)

8 Klein C, Cunningham DA, Paterson DH \& Taylor AW. Fatigue and recovery contractile properties of young and elderly men. European
Journal of Applied Physiology and Occupational Physiology 198857 684-90. (doi:10.1007/BF01075989)

9 Dedrick ME \& Clarkson PM. The effects of eccentric exercise on motor performance in young and older women. European Journal of Applied Physiology and Occupational Physiology 199060 183-186. (doi:10.1007/ BF00839156)

10 Herbert P, Grace FM \& Sculthorpe NF. Exercising caution: prolonged recovery from a single session of high-intensity interval training in older men. Journal of the American Geriatrics Society 201563 817-818. (doi:10.1111/jgs.13365)

11 Knechtle B, Knechtle P, Rosemann T \& Senn O. Personal best time and training volume, not anthropometry, is related to race performance in the 'Swiss Bike Masters' mountain bike ultramarathon. Journal of Strength and Conditioning Research 201125 1312-1317. (doi:10.1519/ JSC.0b013e3181d85ac4)

12 Arazi H, Damirchi A \& Asadi A. Age-related hormonal adaptations, muscle circumference and strength development with 8 weeks moderate intensity resistance training. Annales d'Endocrinologie 2013 74 30-35. (doi:10.1016/j.ando.2012.11.004)

13 Hayes L, Herbert P, Sculthorpe N \& Grace F. Exercise training improves free testosterone in lifelong sedentary aging men. Endocrine Connections 20176 306-310. (doi:10.1530/EC-17-0082)

14 Lovell DI, Cuneo R, Wallace J \& McLellan C. The hormonal response of older men to sub-maximum aerobic exercise: the effect of training and detraining. Steroids 201277 413-418. (doi:10.1016/j. steroids.2011.12.022)

15 O'Donnell AB, Travison TG, Harris SS, Tenover JL \& McKinlay JB. Testosterone, dehydroepiandrosterone, and physical performance in older men: results from the Massachusetts male aging study. Journal of Clinical Endocrinology and Metabolism 200691 425-431. (doi:10.1210/ jc.2005-1227)

16 Flegg JL. The effect of normative aging on the cardiovascular system. American Journal of Geriatric Cardiology 19943 25-31.

17 Lindle RS, Metter EJ, Lynch NA, Fleg JL, Fozard JL, Tobin J, Roy TA \& Hurley BF. Age and gender comparisons of muscle strength in 654 women and men aged 20-93 yr. Journal of Applied Physiology 199783 1581-1587.

18 Hayes LD, Sculthorpe N, Herbert P, Baker JS, Spagna R \& Grace FM. Six weeks of conditioning exercise increases total, but not free testosterone in lifelong sedentary aging men. Aging Male 201518 195-200. (doi:10.3109/13685538.2015.1046123)

19 Sylta O, Tonnessen E, Sandbakk O, Hammarstrom D, Danielsen J, Skovereng K, Ronnestad BR \& Seiler S. Effects of HIT on physiological and hormonal adaptions in well-trained cyclists. Medicine and Science in Sports and Exercise 201749 1137-1146. (doi:10.1249/ MSS.0000000000001214)

20 Weston M, Taylor KL \& Batterham AM. Effects of low-volume highintensity interval training (hit) on fitness in adults: a meta-analysis of controlled and non-controlled trials. Sports Medicine $2014 \mathbf{4 4}$ 1005-1017. (doi:10.1007/s40279-014-0180-z)

21 Sculthorpe NF, Herbert P \& Grace F. One session of highintensity interval training (HIT) every 5 days, improves muscle power but not static balance in lifelong sedentary ageing men: a randomized controlled trial. Medicine 201796 e6040. (doi:10.1097/ MD.0000000000006040)

22 Herbert P, Sculthorpe N, Baker JS \& Grace FM. Validation of a six second cycle test for the determination of peak power output. Research in Sports Medicine 201523 115-125. (doi:10.1080/15438627. 2015.1005294)

23 Herbert P, Hayes LD, Sculthorpe N \& Grace F. High intensity interval training (HIIT) increases insulin-like growth factor-I (IGF-I) in sedentary aging men but not masters' athletes. Aging Male 201720 54-59. (doi:10.1080/13685538.2016.1260108)

24 Hayes LD, Sculthorpe N, Herbert P, Baker JS, Hullin DA, Kilduff LP $\&$ Grace FM. Poor levels of agreement between serum and saliva

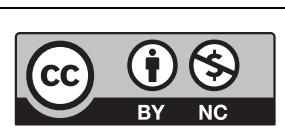

This work is licensed under a Creative Commons Attribution-NonCommercial 4.0 International License. 
testosterone measurement following exercise training in ageing men. Aging Male 201518 67-70. (doi:10.3109/13685538.2015.1018158)

25 Hayes LD, Sculthorpe N, Herbert P, Baker JS, Hullin DA, Kilduff LP \& Grace FM. Resting steroid hormone concentrations in lifetime exercisers and lifetime sedentary males. Aging Male 201518 22-26. (doi:10.3109/13685538.2014.977246)

26 Hayes LD, Sculthorpe N, Herbert P, Baker JS, Hullin DA, Kilduff LP, Reed D, Spagna R \& Grace FM. Salivary testosterone measurement does not identify biochemical hypogonadism in aging men: a ROC analysis. Endocrine 201550 256-259. (doi:10.1007/s12020014-0516-3)

27 Vermeulen A, Verdonck L \& Kaufman JM. A critical evaluation of simple methods for the estimation of free testosterone in serum. Journal of Clinical Endocrinology and Metabolism 199984 3666-3672. (doi:10.1210/jcem.84.10.6079)

28 Kacker R, Hornstein A \& Morgentaler A. Free testosterone by direct and calculated measurement versus equilibrium dialysis in a clinical population. Aging Male 201316 164-168. (doi:10.3109/13685538. 2013.835800)

29 Sheykhlouvand M, Khalili E, Agha-Alinejad H \& Gharaat M. Hormonal and physiological adaptations to high-intensity interval training in professional male canoe polo athletes. Journal of Strength and Conditioning Research 201630 859-866. (doi:10.1519/JSC.0000000000001161)

30 Sperlich B, Zinner C, Heilemann I, Kjendlie PL, Holmberg HC $\&$ Mester J. High-intensity interval training improves $\mathrm{VO}_{2 \text { peak }}$, maximal lactate accumulation, time trial and competition performance in 9-11-year-old swimmers. European Journal of Applied Physiology 2010110 1029-1036. (doi:10.1007/s00421-0101586-4)

31 Wright MD, Hurst C \& Taylor JM. Contrasting effects of a mixedmethods high-intensity interval training intervention in girl football players. Journal of Sports Sciences 201634 1808-1815. (doi:10.1080/ 02640414.2016.1139163)

32 Stöggl T \& Sperlich B. Polarized training has greater impact on key endurance variables than threshold, high intensity, or high volume training. Frontiers in Physiology 20145 3. (doi:10.3389/ fphys.2014.00033)

33 Naimo MA, de Souza EO, Wilson JM, Carpenter AL, Gilchrist P, Lowery RP, Averbuch B, White TM \& Joy J. High-intensity interval training has positive effects on performance in ice hockey players. International Journal of Sports Medicine 201536 61-66. (doi:10.1055/ s-0034-1382054)

34 Adlercreutz H, Harkonen M, Kuoppasalmi K, Naveri H, Huhtaniemi I, Tikkanen H, Remes K, Dessypris A \& Karvonen J. Effect of training on plasma anabolic and catabolic steroid-hormones and their response during physical exercise. International Journal of Sports Medicine 19867 27-28. (doi:10.1055/s-2008-1025798)

35 Fry AC, Kraemer WJ \& Ramsey LT. Pituitary-adrenal-gonadal responses to high-intensity resistance exercise overtraining. Journal of Applied Physiology 199885 2352-2359.

Received in final form 20 July 2017

Accepted 21 July 2017 http://www.endocrineconnections.org DOI: 10.1530/EC-17-0159
(C) 2017 The authors Published by Bioscientifica Ltd

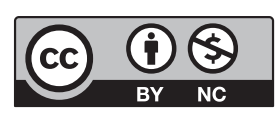

This work is licensed under a Creative Commons Attribution-NonCommercial 4.0 International License. 